\title{
Congestion at Chittagong Seaport: Causes and Consequences. A case study in Malaysia
}

\author{
Redwan Ahamed Kabir ${ }^{1}$ (D), Khalid Helal ${ }^{2}$ (D) \\ ${ }^{1,2}$ International Islamic University Malaysia, Jalan Gombak, 53100, Selangor, Malaysia
}

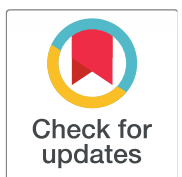

Keywords: Seaport; Congestion; Partial least square-structural equation model; Equipment; IPMA; Chittagong.

Received Date:
01-03-2021

Accepted Date:

04-09-2021

Publication Date:

30-09-2021

\section{ABSTRACT}

Purpose of the study: This study aims to examine the causes of seaport congestion at Chittagong seaport. Seaports are vital instruments of international trade and a key to the economic growth of any country. Seaport congestion is a significant issue faced by most of the seaport. Shipping lines carry the cargo from one seaport to another; seaport congestion faced at the one port has a detrimental effect on the economy and trade of the country.

Methodology: This study used the survey-based data collected design through convenience sampling from the port employees. The collected data were analysed with SmartPLS 3.2.1.

Main Findings: The results of importance-performance matrix analysis (IPMA) reveals that the three most important factors causing the congestion at seaport are information technology, equipment, and time.

Research implications: The study findings advocate that seaport authorities need to improve the information technology use at the seaport as well as the equipment utilised for handling the cargo. However, congestion issues can only be resolved by taking a holistic approach and involving all the stakeholders to improve the Chittagong port efficiency as well as bringing trade growth for the country.

The novelty of the study: Current work is that the data was collected from one seaport only but the analysis supported the arguments that the seaport equipment, labour, and customs significantly contributing to the seaport congestion. However, the impact of the infrastructure and information technology is insignificant on the seaport congestion as perceived by the study respondents.
Copyright: (C) 2021. The Authors. Licensee: IJSSER. This work is licensed under the Creative Commons Attribution License.

Please cite this article as: Kabir, R. A., Helal, K. (2021). Congestion at Chittagong Seaport: Causes and Consequences. International Journal of Social Sciences and Economic Review, 3(3), 1220.

doi.org/10.36923/ijsser.v3i 3.103

\section{Read online:}

Scan this QR code with your smart phone or mobile device to read online.

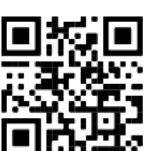

\section{INTRODUCTION}

International trade is the key to global development, and seaports are prime sources of global trade, handling millions of cargo containers yearly (Islam \& Haider, 2016). Seaports connect the world trade, and sea routes are the low-cost option of movements of the good between the countries (Notteboom, 2006). One-third of the global trade made through the sea routes and seaports are the primary hubs of the international trade of today (Zhang, Loh \& Van Tahi, 2015). High competitive environment demands a high level of efficiency from the seaports.

Vessel delays are a harsh reality of global trade, and multiple factors are inflecting the delay or congestion at the seaport level (Nyema, 2014). Ship accidents, fire incidents, and ship grounding are the most common causes of the delay in shipments ( $\mathrm{Lu}$, Shang \& Lin, 2016). However, there is a multitude of factors outside the control of ship liners that are causing congestion at seaports (Welvarrts, 2017). Seaport congestion is caused by operational inefficiency, absence of infrastructure at ports, capacity issues, lack of digitalization at ports, and having insufficient banking and insurance system (Jeevan, Ghaderi, Bandara, Saharuddin, \& Othman, 2015). The economic development of the country is associated with excellent infrastructure and connectivity, enhancing cooperation among the partner countries and gaining maximum benefits for the developing countries (Jiang, Wan \& Zhang, 2016)). Congestion at ports is the phenomenon of queuing, causing delays or additional time requires for the voyage of freight-carrying ships (Yeo, Roe \& Soak, 2007). These delays are causing unpleasant consequences for the logistics and supply chains. The cost of delays occurs in terms of loss of timely delivery, monetary cost, as well as penalties on the trade and shipping agreements (Meersman et al., 2012).

Seaports are essential for the trade of Bangladesh, as $87 \%$ of the trade is handled by the seaport and Chittagong seaport manage the major agriculture imports and exports of the country (Islam \& Haider, 2016). The major challenge faced by seaports is not having deep-sea facilities. Chittagong seaport especially has the insufficiencies of infrastructure to handle the containers (Welvaarts, 2017). Development plans for the port have been not realised yet, the and port significantly lacks in the jetties, yard, and instruments to handle the growing number of containers at the port. Waiting time is high in the port, as only 19 docks are active, and only 15-16 ship vessels can dock each day (Islam \&

${ }^{1}$ Corresponding Author: rakabir@outlook.com 
Haider, 2016). The lack of gantry cranes was also highlighted many times. Chittagong port choked many times and reported blamed the importer, clearing, and forwarding agents for not proving the

clear timeline (Welvaarts, 2017). However, the port authorities are also unable to expand the jetties, yard, or other relevant operational equipment.

\section{LITERATURE REVIEW}

\subsection{Seaport operations \& congestion}

Transportation of trade goods by sea remains the most common mode of global trade to date. The shipping industry follows the guidelines called the international standard of maritime. According to the international standard of maritime, seaports are the gateway of the international trade and acts as a focal point for the movement of goods on land by means of the rail and road; seaports are initiator commercial activities like banking services; freight forwarding; clearing and other associated services of trading as well as to boost the economic activities, ports are the hub of distribution where excellent or consolidated and cargo services generate the value of the trade; lastly, effective ports operation multiply the economic activities and job creation (Jeevan et al., 2015; Nyema, 2014).

Moreover, port operation helps to control the movement of goods in and out of the country. Customs authorities manage the movement of goods according to prevailing laws and regulations of the country (Luo \& Yip, 2013). Documentary evidence helps the movement of goods, as well as trade, helps the country economic activities and source of income for governments (Islam \& Haider, 2016). The operations of the seaport help the loading and unloading of goods containers. Seaports help dock the sea ships and park the goods for storage as well (Nyema, 2014).

Port congestion is a scenario of allied queuing, taking extra time or delays caused in the voyage and lodge time of the cargo ships at the seaports (Jiang et al., 2016). The noteworthy waiting time indicators of the cargo ships at seaports are cargo ship waiting time to dock, operational waiting time, storage waiting time, and in total, called the transactional time between the import and delivery to the customer (Nazemzadeh \& Vanelslander, 2015). Port congestion cost severely on the logistics, supply chains, as well as on the environment (Luo \& Yip, 2013).

\subsection{Factors Causing Congestion Seaport}

Seaport congestion is the issue faced by many of the seaports around the globe. We here added the significant issues of the seaport congestion as the congestion occurs due to the shortage of the ship berths on the seaport. Ship berths are the area where ship harbours, and then the containers are offloaded or loaded on the ship vessels (Yeo et al., 2007). The berth capacity is the critical issue increasing the waiting time for the ship to harbour at the seaport. The next associated area causing the congestion is the time taken on the loading or unloading of container terms as ship work congestion (Nyema, 2014). The inefficient working of labour and equipment, causing ship congestion at seaports (Luo \& Yip, 2013). The time to load or unload increased the time of the ship to keep on the harbour. The seaport exit or entry route is sometimes blocked due to mismanagement or by mistake (Notteboom, 2006). This not only blocks the route and causing queuing or bunching and forced the ships to overstay in the port facilities. Other than the reason, as mentioned earlier for seaport congestion. Industrial action by port labour, lack of equipment, delay in the documentation, and shortage of storage capacity are some common reasons causing the congestion at seaports (Meersman et al., 2012).

Corruption became a routine activity among the Chittagong port authority (Mahmud \& Rossette, 2007), and bribery is a practice to get the good cleared on time. Political parties, through labour unions, control the working of ports operations (Islam \& Haider, 2016). Accountability is non-existent at the port, and inadequate and incompetent management also causing the delay, even halt of the operation at the port (Mahmud \& Rossette, 2007). The labour involved in many unethical and unaccepted practices of threatening the management and making unnecessary delays in port operation even damaging the container for the parties not willing to offer tips or bribe to the labour or management staff (Islam \& Haider, 2016).

Insufficiency of the infrastructure is the biggest hurdle for the operations of the seaports. Container handling capacity restricts the optimal operation of the port and also causes congestion (Yeo et al., 2007). However, seaport operational inefficiency is also caused by multiple factors like lack of updated equipment concerning increasing port operations, inefficient labour, and redtapism on the part of the government agencies handling the cargo. Sustainable growth is only possible with the consistent cooperative working of the stakeholders (Lu et al., 2016).

It is vital to take note that port congestion is a universal phenomenon (Meersman et al., 2012). However, port congestion is mainly related to the increase in waiting time due to working over the capacity of the port (Nazemzadeh \& Vanelslander, 2015). Like the Canadian west coast increasingly facing congestion issues, but the primary reason is the increase of shipments from Asia, causing the serve challenges of goods transportation at port (Ke, Li \& Hipel, 2012). The shortage of terminal and labour are among the two critical issues faced by the port (Lu et al., 2016). Insufficient rail and road infrastructure caused the congestion as trade volume increases, and expansion was not made at the rate as the trading volume increases (Nyema, 2014). Strategic expansion of the port is the real solution to reduce the congestion along with improving the efficiency of the port operations.

\subsection{Equipment}

Cargo handling equipment is an essential part of seaport operations. Seaport equipment loads and unloads the cargo container from the cargo ships. Seaport equipment like cranes, forklifts, and trucks carry the cargo container in or out of the seaport (Welvaarts, 2017). Port handling equipment helps the berth operation and allows the handling of cargo vessels (idado, 2015). 
Loading and unloading of cargo containers performed by the cranes and effective use of ports operation depend on the cranes (Nyema, 2014). Forklifts help the movement and staking of cargo containers as the port operations are complex and heavily dependent on the right number of equipment in good working conditions (Ke et al., 2012). However, the lack of proper port equipment massively reduces the work efficiency of the port. We proposed the following hypothesis:

Hypothesis (H1): Port equipment has a positive and significant effect on the perception of port congestion.

\subsection{Infrastructure}

Working beyond the capacity of the port infrastructure is also a primary reason causing the congestion at ports (Moon, 2018). The value chain at the port level base on the availability of port infrastructure (Nazemzadeh \& Vanelslander, 2015). The land, storage space, cargo transfer, and handling capacity of containers are the infrastructure that reflects the operational capacity of the port (Jeevan et al., 2015). However, the congestion at the port is caused by the lack of infrastructure when a seaport attempt to work beyond available capacity (Nyema, 2014). Infrastructure requires strategic investment to enhance the overall handling capacity of the port and improvement in eth overall performance of the port operations (Meersman et al., 2012). Seaport works for the value creation of the traders, and infrastructure significantly reduces the efficiency of the seaport. Therefore, we forwarded the following hypothesis:

\section{Hypothesis (H2): Infrastructure has a positive and significant effect on the perception of port congestion.}

\subsection{Information technology}

Information technology making its mark on all walks of life. Information technology not only helps the smooth operations of the port but also helps for the future planning of the port operations (Nyema, 2014). Research shows that the operational

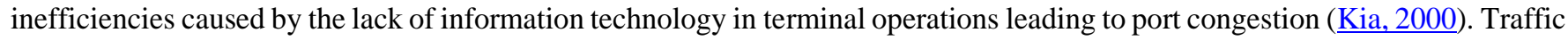
management, as well as allocating the entry and exit at port managed by the information technology (Moon, 2018). Information technology helps the consistent and reliable working of the seaport operation (Nyema, 2014). Right investment in the information technology facilities all the seaport stakeholders (Moon, 2018). Ships scheduling is expressively streamlined by the use of information technology, and sustainability of port operation significantly rely on the use of information technology ( $\underline{\mathrm{Lu}}$ et al., 2016). Henceforth, information technology enables the smooth working of the port operation for all the stakeholders' satisfaction (Zhang et al., 2015). The above discussion prompts us to forward the following hypothesis:

Hypothesis (H3): Information technology has a positive and significant effect on perceptions of port congestion.

\subsection{Labour}

How a seaport operates and organizes its labour can be a crucial factor in its performance or competitiveness (Aryee, 2011). Skilled and well-equipped labour empowers the smooth working of the seaport and promotes the timely operations of the port; it helps to reach the good at the earliest time (Knemeyer, 2006). Labour is the vital operational instrument of the seaports operations. Vessel and yard operations significantly depend on skilled and motivated labour. Efficient labour ensures the required level of services provided to seaport customers (Jiang et al., 2016). Services quality rests on the efficiency of the port workforce and creates a win-win situation for the port and seaport stakeholders (Nyema, 2014). We propose the following hypothesis:

\section{Hypothesis (H4): Labour has a positive and significant effect on perceptions of port congestion.}

\subsection{Time}

Time is the critical factor associated with the movement of logistics at the right time can significantly impact the cost of container movement (Moon, 2018). Ports are at the centre of the goods movement from the consignee, shipper, and consigner perspective. Ports are the processing point of the cargo interchange, logistics operations, and offering valuable services to shippers and consignees (Jeevan et al., 2015). Smooth and reliable port operations reduce the time and cost of the cargo movement (Nyema, 2014). Ports offer services like transportation, warehousing, cargo container handling with the right processing of information (Islam \& Haider, 2016). Operational excellence enables the timely delivery of cargo services to its stakeholders. Time delays in the port logistics cascades and significantly caused port congestion (Moon, 2018). Reliable and efficient services ensure the smooth working of the port operation and the highest level of services to its customers (Nyema, 2014). Following hypothesis proposed:

Hypothesis (H5): Time has a positive and significant effect on perceptions of port congestion.

\subsection{Customs}

The Customs department administers the international trade of a country. Competent and efficient customs authorities ensure the compliance of the national laws and regulatory requirements of international trade (Moon, 2018). Custom authorities of Chittagong port perform the clearance and release of the goods according to the standard operating procedures (Islam \& Haider, 2016). However, stakeholders unduly influence to get the clearance or release of the goods (Mahmud \& Rossette, 2007). The revision of customs rules and procedures facilities the timely clearance of the goods and resolve the issue among the port authorities and the importer or exporter agents (Lu et al., 2016). Government agencies need to handle the situation promptly and provide edural support to port authorities, shipping agents, and C\&F agents to get the clear and release of goods at the earliest (Nyema, 2014). It not only facilitates international trade as well as promotes the smooth working of ports and reduces the congestion at the seaport. The last hypothesis for the study is as follows: 


\section{Hypothesis (H6): Customs authorities working has a positive and significant effect on perceptions of port congestion}

\section{RESEARCH METHODOLOGY}

This study engaged a cross-sectional design and quantitative method to scrutinise the factor influencing congestion at Chittagong seaport. Data was collected through the structured survey from the different stakeholders of the seaport. The collected data were analysed by the use of Statistical Package Social Science (SPSS) for fundamental analysis and PLS-SEM utilised for hypothesis testing.

\subsection{Sample Size}

The target population for this very study was the stakeholder of the Chittagong Seaport. The employees, workers, shipping agents, customs officers, and freight forwarding agents. For the study, we use the Gpower 3.1. to calculate the required sample size. The required sample size with the power of $95 \%$, having six predictors having the medium effect size is 146 . An interviewbased survey was conducted to collect the data from the samples. List of the employee and different stakeholders working on the seaport secured. In total, 260respondentst were data utilised for the final analysis.

\subsection{Research Instrument}

The questionnaire instrument was designed in English and Bangla languages. Questions for construct causing the congestion (equipment, infrastructure, information technology, labour union, time, and customs) were adapted from previous literature and dissertation. Items for equipment, Infrastructure and customs were adopted from Nyema (2014) and Nazemzadeh \& Vanelslander (2015). The Information technology was supported by Kia (2000), and the labour union affirmed from Aryee (2011). In addition, time is explained by Moon (2018). A five-point Likert scale (1 to 5, from "strongly disagree" to "strongly agree") was used for the dependent variable and a five-point Likert scale (1 to 5, from "strongly disagree" to "strongly agree") was used for all variables.

Table 1

Construct No. of items and sources

\begin{tabular}{|l|l|l|}
\hline \multicolumn{1}{|c|}{ Variable } & Items & Source \\
\hline Equipment & 5 & $\underline{\text { Nazemzadeh \& Vanelslander (2015) \& Nyema (2014). }}$ \\
\hline Infrastructure & 6 & $\underline{\text { Nazemzadeh \& Vanelslander (2015) \& Nyema (2014). }}$ \\
\hline Information Technology & 1 & $\underline{\text { Kia \& Shayan \& Ghost }(2000)}$ \\
\hline Labour union & 1 & $\underline{\text { Aryee (2011) }}$ \\
\hline Time & 3 & $\underline{\text { Moon (2018) }}$ \\
\hline Customs & 4 & $\underline{\text { Nazemzadeh \& Vanelslander (2015) \& Nyema (2014). }}$ \\
\hline Congestion & 1 & $\underline{\text { Meersman et al., (2012) }}$ \\
\hline
\end{tabular}

\subsection{Assessment of Common Method Variance (CMV)}

Scientific measurement techniques in social sciences research allied to traditional approaches of data collection that caused the distortion (Podsakoff, Mackenzie Lee \& Podsakoff, 2003). The suggested solution for accessing the effect of CMV on the research constructs was Harman's (1976) one-factor check (Podsakoff et al., 2003). Use of Harman's single factor test suggests that the CMV is not a crucial problem for this analysis as the single factor extraction was about 28 percent than the proposed limit of 50 percent.

\subsection{Multivariate Normality}

Testing the data for the multivariate normality is a requirement to employ the SEM-PLS, as the PLS-SEM it is a nonparametric statistical tool (Hair, Risher, Sarstedt \& Ringle, 2019).

Nonetheless, on the advice of Peng and Lai (2012), an online website web power used to confirm data normality. The test results indicated that the data set non-normal as the Mardia coefficient p-values are less than 0.05 (Cain, Zhang \& Yuan, 2017).

\subsection{Data Analysis Method}

Modeling of partial least squares structural equation (PLS-SEM) with the Smart-PLS 3.1 program was used to test the data collected from the respondents. PLS-SEM is a multivariate exploratory method for analyzing route structures of integrated latent constructs (Hair et al., 2019). PLS-SEM empowers the researcher to manipulate both the non-normal and restricted data collection. In comparison, PLS-SEM is linked with the casual-predictive aspects that allow us to perform complex analysis based on composites and has no postulation of goodness-of-fit calculation as in SEM-based in covariance analysis (Chin, 2010). Data analysis PLS-SEM was postulated to perform the analysis in two phases. The first step was taken to deals with model estimation, where the research construct's reliability and validity were tested (Hair et al., 2019) and model quality obtain through the old and newly developed approaches (Fornel \& Larcker, 1981; Henseler et al., 2015). Step two deals with the evaluation of correlations of the models as well as systemic testing of the study model. Study analysis performed with $\mathrm{r}^{2}, \mathrm{Q}^{2}$, and effect size $\mathrm{f}^{2}$ can explain the change in endogenous construct caused by the exogenous constructs (Hair et al., 2019). 
Importance-performance matrix analysis (IPMA) designates the exogenous model constructs to be comparatively high or low by the endogenous construct's importance and performance (Chin, 2010). IPMA defines and distinguishes the philosophical structure that can maximize the endogenous construct output from both the management and the academic point of view. In the unstandardized method, IPMA draws on the cumulative impact of the rescaled variables scores (Ringle \& Sarstedt, 2016). Rescaling is defined as a score between 0 and 100 for every exogenous latent variable. The mean value of the exogenous latent variable scores represents the performance of the endogenous latent construct, where 0 is the minimum, and 100 is the most significant endogenous construct in terms of efficiency (Hair et al., 2019).

\section{DATA ANALYSIS}

\subsection{Descriptive Statistics}

For the study data was collected from the Bangladeshi individuals working as employees, terminal operators, or clearing and forwarding agents at the Chittagong seaport. Among the respondents, 37.4\% have the age between 20-29 years; the respondents having the age between $30-39$ years are $30.4 \%$, respondents having the age between $40-49$ are $18 \%$, and remaining have the age 50 or above. The majority of respondents have a college degree, with $48.1 \%$ of the total respondents. Respondents completed for the university degree are $21.9 \%$, respondents have the primary and secondary school level education are $13.5 \%$, and $12.7 \%$, respectively.

Among the respondents, the majority of respondents have 1-4 years of working experience, with $42.7 \%$ of total respondents. $39.6 \%$ of the respondents have 5-10 years of working experience, and the remaining respondents have more than 10 years of experience. The vast majority of the respondents are working as full-time employees; $60 \%$ of the respondent are full-time workers. Part-time and contractual workers are $17.3 \%$ and $22.6 \%$, respectively. We collected the data from the equally representative of the different occupations working at the seaport.

Table 2

Profile of the Respondents

\begin{tabular}{|c|c|c|c|c|c|}
\hline & $\mathbf{n}$ & $\%$ & & $\mathbf{n}$ & $\%$ \\
\hline Education & & & Age & & \\
\hline Primary & 35 & 13.5 & 20- 29 years of age & 97 & 37.4 \\
\hline Secondary & 33 & 12.7 & 30-39 years of age & 79 & 30.4 \\
\hline Degree & 125 & 48.1 & $40-49$ years of age & 47 & 18.0 \\
\hline University & 57 & 21.9 & 50 and above of age & 37 & 14.2 \\
\hline Total & 260 & 100 & Total & 260 & 100 \\
\hline Work Experience & & & Occupation & & \\
\hline $1-4$ years & 111 & 42.7 & C\&F agents & 66 & 25.4 \\
\hline 5-10 years & 103 & 39.6 & Labour union & 65 & 25.0 \\
\hline 11 years or more & 46 & 17.6 & Terminal Operator & 64 & 24.6 \\
\hline \multirow[t]{2}{*}{ Total } & 260 & 100 & Freight forwarders & 65 & 25.0 \\
\hline & & & Total & 260 & 100 \\
\hline \multicolumn{6}{|l|}{ Jobs } \\
\hline Full time & 156 & 60 & & & \\
\hline Part-time & 45 & 17.3 & & & \\
\hline Contract basis & 59 & 22.6 & & & \\
\hline Total & 260 & 100 & & & \\
\hline
\end{tabular}

Source: Calculated by the author.

\subsection{Validity and Reliability}

Utilizing the recommendation of Hair et al. (2019), we conduct and reporting the Smart PLS results. Study's constructs reliabilities estimated with composite reliability (CR). The results demonstrate that all the ÇR scores are in the acceptable range. The minimum value (CR) was 0.717 for the infrastructure construct. The results are reported in Table 2. These outcomes indicate that the model constructs are reliable. AVE for all the constructs must be above the threshold of 0.50 score to institute the convergent validity as an indication of the uni-dimensionality for each construct (Hair et al., 2019). Variance inflation factor (VIF), for each construct reported in Table 2, all the VIF values are less than 3.3, instituting the lack of multi-collinearity issues for the model constructs'. Items display that constructs have acceptable convergent validity (see Table 2.). The item loading and cross-loading were reported for validation of construct discriminant validity. The study constructs have acceptable discriminant validity (See Table 3).

Additionally, the Fornell-Larcker criterion (1981) and Hetro-trait \& mono-trait, HTMT ratio test, utilised to confirm the study constructs has the discriminant validity. Results of the Fornell-Larcker criterion for each construct must be higher for its own

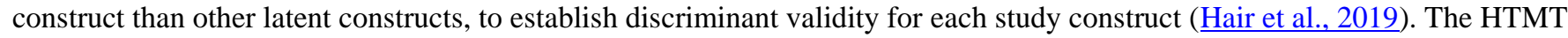
ratio essentially is less than 0.85 to provide the evidence for discriminant validity for study constructs ( Table 3 shows that the study has discriminant validity. 
Table 3

Reliability analysis

\begin{tabular}{lcccc} 
Variables & $\begin{array}{c}\text { Number of } \\
\text { Items }\end{array}$ & $\begin{array}{l}\text { Composite } \\
\text { Reliability }\end{array}$ & $\begin{array}{c}\text { Average } \\
\text { Variance } \\
\text { Extracted }\end{array}$ & $\begin{array}{l}\text { Variance } \\
\text { Inflation } \\
\text { Factor }\end{array}$ \\
\hline Equipment & 4 & 0.773 & 0.631 & 1.745 \\
\hline Infrastructure & 2 & 0.717 & 0.560 & 1.910 \\
\hline Information Technology & 1 & 1.000 & 1.000 & 2.096 \\
\hline Labour & 1 & 1.000 & 1.000 & 1.721 \\
\hline Time & 1 & 0.705 & 0.556 & 1.284 \\
\hline Customs & 2 & 0.767 & 0.622 & - \\
\hline Port Congestion & 1 & 1.000 & 1.000 &
\end{tabular}

Table 4

Outer Loading and Cross Loadings

\begin{tabular}{|c|c|c|c|c|c|c|c|}
\hline & EQP & INS & ITN & LBR & TME & CUS & PCP \\
\hline \multicolumn{8}{|c|}{ Fornell-Larcker Criterion } \\
\hline EQP & 0.794 & & & & & & \\
\hline INS & 0.066 & 0.748 & & & & & \\
\hline ITN & -0.005 & 0.118 & 1.000 & & & & \\
\hline LBR & 0.225 & -0.112 & -0.094 & 1.000 & & & \\
\hline TME & 0.138 & 0.002 & -0.089 & -0.070 & 0.745 & & \\
\hline CUS & -0.108 & -0.041 & 0.078 & 0.161 & -0.236 & 0.789 & \\
\hline PCP & 0.156 & -0.124 & 0.010 & 0.401 & -0.272 & 0.215 & 1.000 \\
\hline
\end{tabular}

Heterotrait-Monotrait Ratio (HTMT)

\begin{tabular}{lcc}
\hline EQP & - & \\
\hline INS & 0.850 & - \\
\hline ITN & 0.100 & 0.247 \\
\hline LBR & 0.670 & 0.247 \\
\hline TME & 0.499 & 0.17 \\
\hline CUS & 0.247 & 0.305 \\
\hline PCP & 0.236 & 0.236
\end{tabular}

0.247

$0.247 \quad 0.094$

$0.146 \quad 0.148$

$\begin{array}{lll}0.305 & 0.125 & 0.256\end{array}$

$0.236 \quad 0.010 \quad 0.401$

0.664

0.341

0.343

Note: EQP: Equipment; INS: Infrastructure; ITN: Information Technology; LBR: Labour; TME: Time; CUS: Customs; PCP: Port Congestion.

\subsection{Path Analysis}

Afterwards, the model measurement is achieved after the attainment of model validity and reliabilities. In this step, the impact of the entertainment, interaction, trendiness, and customization, on the value equity, relational equity, and brand equity. The adjusted $r^{2}$ value for the six exogenous constructs (i.e., equipment, infrastructure, information technology, labour, time, and customs) explains the 23.6 percent of change in perceived port congestion.

Table 5

Hypothesis testing

\begin{tabular}{lccccccc}
\hline & Hypothesis & Coefficient & t-values & Sig. & $\boldsymbol{r}^{\mathbf{2}}$ & $\boldsymbol{f}^{\mathbf{2}}$ & Decision \\
\hline H1 & EQP $\rightarrow$ PCP & 0.134 & 2.905 & 0.002 & & 0.022 & Supported \\
\hline H2 & INS $\rightarrow$ PCP & -0.093 & 1.443 & 0.075 & 0.011 & Not Supported \\
\hline H3 & ITN $\rightarrow$ PCP & 0.023 & 0.458 & 0.323 & 0.001 & Not Supported \\
\hline H4 & LBR $\rightarrow$ PCP & 0.327 & 4.978 & 0.000 & & 0.127 & Supported \\
\hline H5 & TME $\rightarrow$ PCP & -0.238 & 4.014 & 0.000 & & 0.070 & Supported \\
\hline H6 & CUS $\rightarrow$ PCP & 0.115 & 2.036 & 0.021 & 0.253 & 0.016 & Supported
\end{tabular}

Note: EQP: Equipment; INS: Infrastructure; ITN: Information Technology; LBR: Labour; TME: Time; CUS: Customs; PCP: Port Congestion.

Study standardised path values, t-values, and significance level depicted in table 4 . The path coefficient between EQP and PCP $(\beta=0.134, p=0.002)$, indicating a significant and positive effect of the EQP on the PCP. This result offers statistical sustenance to accept the H1. The path value for the INS and PCP $(\beta=-0.093, p=0.075)$, display the impact of the INS on the PCP as negative but insignificant, thus provides no statistical support for the $\mathrm{H} 2$. The path value for the ITN and PCP $(\beta=0.023, p=$ 0.323), shows the impact of the ITN on PCP comes non-significant but positive, thus provides no statistical support for the H3. The influence of the LBR on the PCP $(\beta=0.327, p=0.000)$, depicting the effect of the LBR on the PCP as positive and significant as well; it offers the sstical evidence to support the H4. The path coefficient between TME and PCP $(\beta=-0.238, p=$ 0.000), indicating a significant negative effect of the TME on the PCP. These results have no statistical support to accept H5. Moreover, the path coefficient for the CUS and PCP $(\beta=0.115, p=0.021)$, depicting the effect of CUS on the PCP as positive and significant; provides the statistical indication to support the H6. Path coefficients are shown in Table 4. 


\subsection{Importance-Performance Matrix Analysis (IPMA)}

Outcomes of the IPMA are revealed in Table 5, and it shows that the ITN is the most crucial factor in the performance of the PCP with the score of $(0.084 ; 80.00)$; the second most crucial factor for the performance of the PCP with the score of $(0.700$; $61.709)$ is the EQP. The third most important factor in the performance of PCP is the TME with a score of $(-0.559,59.784)$. The fourth factor for the performance of the PCP is the CUS with a score of $(0.380 ; 38.431)$. The fifth most significant factor in the performance of PCP is the LBR with a score of $(0.463 ; 37.051)$. Moreover, the sixth most significant factor in the performance of PCP is the INS with a score of $(-0.275 ; 35.324)$.

Table 6

Importance-Performance Matrix

\begin{tabular}{lcc}
\hline Target Construct & PCP & Performance \\
\hline Variables & Total Effect & 61.709 \\
\hline EQP & 0.700 & 35.324 \\
\hline INS & -0.275 & 80.000 \\
\hline ITN & 0.084 & 37.051 \\
\hline LBR & 0.463 & 59.784 \\
\hline CUS & -0.559 & 38.431 \\
\hline
\end{tabular}

Note: EQP: Equipment; INS: Infrastructure; ITN: Information Technology; LBR: Labour; TME: Time; CUS: Customs; PCP: Port Congestion.

\section{DISCUSSION}

Study results offer support for the arguments that equipment, infrastructure, information technology, labour, time, and customs are essential contributors to the port level congestion as perceived by different stakeholders of the Chittagong seaport. The effect of labour $\left(f^{2}=0.127\right)$ on the PCP is a significant medium effect on the PCP. Such as equipment $\left(f^{2}=0.022\right)$ and time $\left(f^{2}=0.070\right)$ have small and significant effect on perceived PCP. Results of the study correspond with finding reported by Knemeyer (2006) that labour is an important factor that works well, empowers the seaport to have efficiency, the inefficiency of the labour generates the congestion at the seaport. Our study results collaborate with the finding of Gidado (2015) that the equipment helps the optimal performance of the seaport as the Chittagong seaport is experiencing a lack of equipment. This significantly induces seaport congestion at the Chittagong seaport. However, the inefficiency caused by multiple factors leads to the time taken for the operation of the seaport clearance of the goods. Jeeven et al. (2015) reported that the inefficiency at the seaport increases the time taken for the processing of the cargo and cause congestion at the seaport.

Moreover, the effect of infrastructure $\left(f^{2}=0.011\right)$, information technology $\left(f^{2}=0.001\right)$, and customs $\left(f^{2}=0.016\right)$ have less than small effect on the PCP (Cohen, 1988). The study findings match with results reported by Yeo et al. (2007) that the port operation is significantly impacted by the capacity of the infrastructure. The lack of infrastructure caused the congestion as the handing capacity of the port to remain less than the goods container arriving or going out of the seaport. Customs authorities cause congestion in seaport operations. At the Chittagong seaport, information technology is playing a significant role in the congestion of seaport, study findings identical to results reported by Lu et al. (2016). Information technology can facilitate seaport operation and helps to reduce seaport congestion. However, the customs staff also affect the working of the seaport and cause congestion. Our findings match with the work of Zhang et al. (2015) that customs staff needs to be vigilant and facilitate the smooth working of the seaport. The trade and industry of the country heavily rely on the efficient working of the seaport. Therefore, it is imperative that the customs staff made every attempt to reduce the congestion at the seaport and not became a source of it.

Moreover, IMPA results show that the three most significant factors that impact the PCP at the Chittagong seaport are ITN, EQP, and TME. The identification of these factors helps to track and correct these for the smooth operations of the seaport.

\section{CONCLUSION}

Seaports are the hub of trade and commerce among the countries. Inefficient and working under capacity are the common issues faced by the seaports and causing seaport congestions. The performance of the seaport operations shows the efficient working of the national economy (Nyema, 2014). The efficiency became the real tool to gauge the trade performance of the economies. Multiple factors create seaport congestion, and multilateral and cohesive policy guidelines can only enhance the work efficiency at the seaports.

Right policy-making, in collaboration with the stakeholders, can benefit the operations of the seaport. Port authorities need to work closely with the customs and labour unions to smooth line seaport operation as well as improving the port capacity by enhancing the port equipment and infrastructure. In the technology era, information technology can facilitate the ship's movement at the port as well as cargo handling. Investment in information technology helps the seaport in multiple ways facilitating the freight forwarder and customer alike. Enhanced use of information technology reduces the unnecessary powers of the customs and manipulation of the labour unions. Perception of seaport congestion is significantly reduced by the enhanced role of information technology at the seaport.

Notwithstanding having its strengths, the study has the subsequent three perimeters. The study's data was collected in a crosssectional manner from different stakeholders of the Chittagong seaport. This would add more insights if the data were longitudinally collected from different sources. This offers to have the broader generalizability of the study results. Another 
limitation associated with the current work is that the data was collected from one seaport only. It would be interesting to study the same issues in other seaports as well. It helps to creates generalisation for the factors causing congestion at seaports. The third limitation is associated with the selection of samples for the study. The inclusion of other seaport management use of the focus group can enable to explore the relevant sources of the congestion from the management point of view. The triangulation of argument helps to have a better view of reality related to the congestion faced at the Chittagong seaport. Moreover, the sustainability of seaports concerning the triple bottom line paradigm needs to explore as well.

\section{REFERENCES}

Aryee, J. (2011). Analysis of the Role of Port Labour Systems and Reforms on the Competitiveness of West Africa Ports. Available at SSRN 2625137. 1, 24. https://doi.org/10.2139/ssrn.2625137

Cain, M. K., Zhang, Z., \& Yuan, K. H. (2017). Univariate and multivariate skewness and kurtosis for measuring nonnormality: Prevalence, influence and estimation, Behav Res. 49(5), 1716-1735. https://doi.org/10.3758/s13428-016-0814-1

Cohen, J. (1988). Statistical Power Analysis for the Behavioral Sciences (2nd ed.). Lawrence Erlbaum Associates.

Fornell, C., \& Larcker, D. F. (1981). Evaluating Structural Equation Models with Unobservable Variables and Measurement Error. Journal of marketing research, 18(1), 39-50.

Gidado, U. (2015). Consequences of Port Congestion on Logistics and Supply Chain in African Ports. Developing Country Studies, 5(6), 160-167.

Hair, J. F., Risher, J. J. R., Sarstedt, M., \& Ringle, C. M. (2019). When to use and how to report the results of PLS-SEM. European business review, 31(1), 2-24.

Harman, H. H. (1976). Modern Factor Analysis (3rd ed.). University of Chicago Press.

Henseler, J., Ringle, C. M., \& Sarstedt, M. (2015). A new criterion for assessing discriminant validity in variance-based structural equation modeling. Journal of the academy of marketing science, 43(1), 115-135.,

Islam, M. A., \& Haider, M. Z. (2016). Performance assessment of Mongla seaport in Bangladesh. International Journal of Transportation Engineering and Technology, 2(2), 15-21.

Jeevan, J., Ghaderi, H., Bandara, Y. M., Saharuddin, A. H., \& Othman, M. R. (2015). The implications of the growth of port throughput on the port capacity: The case of Malaysian major container seaports. International Journal of e-Navigation and Maritime Economy, 3, 84-98. https://doi.org/10.1016/j.enavi.2015.12.008

Jiang, C., Wan, Y., \& Zhang, A. (2016). Internalization of port congestion: Strategic effect behind shipping line delays and implications for terminal charges and investment. Maritime Policy \& Management, 44(1), 112-130. https://doi.org/10.1080/03088839.2016.1237783

Kia, M., Shayan, E., \& Ghotb, F. (2000). The importance of information technology in port terminal operations. International Journal of Physical Distribution \& Logistics Management. 30(3/4), 331-344. https://doi.org/10.1108/09600030010326118

Krejcie, R. V., \& Morgan, D. W. (1970). Determining Sample Size for Research Activities. Educational and psychological measurement, 30(3), 607-610. https://doi.org/10.1177/001316447003000308

Lu, C. S., Shang, K. C., \& Lin, C. C. (2016). Identifying crucial sustainability assessment criteria for container seaports. Maritime Business Review, 1(2), 90-106. https://doi.org/10.1108/mabr-05-2016-0009

Luo, M., \& Yip, T. L. (2013). Ports and the Environment. Maritime Policy \& Management, 40(5), $401-403$. https://doi.org/10.1080/03088839.2013.797122

Mahmud, T., \& Rossette, J. (2007). Problems and potentials of Chittagong Port: a follow-up diagnostic study. Transparency International Bangladesh (TIB), 1-6. https://www.ti-bangladesh.org/beta3/index.php/en/research-policy/92diagnostic-study/499-problems-and-potentials-of-chittagong-port-a-follow-up-diagnostic-study

Meersman, H., Voorde, E. V. de, \& Vanelslander, T. (2012). Chapter 4: Port Congestion and Implications to Maritime Logistics. In Maritime Logistics: Contemporary Issues (pp. 49-68). Emerald Group Publishing Limited. https://www.emerald.com/insight/publication/doi/10.1108/9781780523415

Michael, K., A. (2006). Logistics and supply chain management: Creating value-adding networks. 45(1), 61-62.

Moon, D. (2018). Port performance indicators (PPI) and analysis-Introduction. World Maritime University. https://issuu.com/worldmaritimeuniversity/docs/academic-handbook/31

Nazemzadeh, M., \& Vanelslander, T. (2015). The container transport system: Selection criteria and business attractiveness for North-European ports. Maritime Economics \& Logistics, 17(2), 221-245. https://doi.org/10.1057/mel.2015.1

Notteboom, T. (2006). The Time Factor in Liner Shipping Services. Maritime Economics \& Logistics, 8(1), 19-39. https://doi.org/10.1057/palgrave.mel.9100148

Nyema, S. M. (2014). Factors influencing container terminals efficiency: A case study of Mombasa entry port. European Centre for Research Training and Development UK, 2(3), 39-78.

Peng, D. X., \& Lai, F. (2012). Using partial least squares in operations management research: A practical guideline and summary of past research. Journal of operations management, 30(6), 467-480. https://doi.org/10.1016/j.jom.2012.06.002

Podsakoff, P. M., MacKenzie, S. B., Lee, J.-Y., \& Podsakoff, N. P. (2003). Common method biases in behavioral research: A critical review of the literature and recommended remedies. Annual review of psychology, 88(5), 879-903. https://doi.org/10.1037/0021-9010.88.5.879

Ringle, C. M., \& Sarstedt, M. (2016). Gain more insight from your PLS-SEM results: The importance-performance map analysis. Industrial management \& data systems, 116(9), 1865-1886. https://doi.org/10.1108/IMDS-10-2015-0449

Vinzi, V. E., Chin, W. W., Henseler, J., \& Wang, H. (Eds.). (2010). Handbook of Partial Least Squares. Springer-Verlag Berlin Heidelberg. https://doi.org/10.1007/978-3-540-32827-8 29 
Welvaarts, W. (2017). Strategic Master Plan for Chittagong Port [Assessment]. Asian Development Bank. https://www.adb.org/sites/default/files/project-documents/45078/45078-001-tacr-en.pdf

Yeo, G.-T., Roe, M., \& Soak, S.-M. S. (2007). Evaluation of the Marine Traffic Congestion of North Harbor in Busan Port. Journal of Waterway, Port, Coastal, and Ocean Engineering, 133(2), 87-93.

Y.Ke, G., Li, K. W., \& Hipel, K. W. (2012). An integrated multiple criteria preferences ranking approach to the Canadian west coast port congestion conflict. Expert Systems with Applications, 39(10), 9181-9190. https://doi.org/10.1016/j.eswa.2012.02.086

Zhang, A., Loh, H. S., \& Thai, V. V. (2015). Impacts of Global Manufacturing Trends on Port Development: The Case of Hong Kong1. The Asian Journal of Shipping and Logistics, 31(1), 135-159. https://doi.org/10.1016/j.ajsl.2015.03.006 